\title{
On some fixed point theorems for implicit almost contractive mappings
}

\author{
VALERIU POPA
}

\section{ABSTRACT.}

In this paper a general fixed point theorem for pairs of general almost contractive mappings satisfying an implicit relation is proved. In the last part of the paper is proved that the fixed point problem for these pairs of mappings is well posed.

\section{REFERENCES}

[1] Abbas, M. and Jungck, G., Common fixed point results for noncommuting mappings without continuity in cone metric spaces, J. Math. Ann. Appl., 341 (2008), 416-420

[2] Abbas, M. and Jungck, G., Common fixed point results for noncommuting mappings without continuity in generalized metric spaces, Appl. Math. and Computation, 215 (2009), 262-269

[3] Abbas, M., Babu, G. V. R. and Alemayehu, G. N., On common fixed point results of weakly compatible mappings satisfying generalized conditions B, Filomat, 25 (2011), No. 2, 9-19

[4] Akkouchi, M. and Popa, V., Well - posedness of common fixed point problem for three mappings under strict contractive conditions, Bull. Math. Inf. Physics Series, Petroleum - Gas Univ. Ploieşti, 61 (2009), No. 2, 1-10

[5] Akkouchi, M. and Popa, V., Well - posedness of a fixed point problem using $G$ - functions, Sci. Stud. Res. Ser. Math., Univ. V. Alecsandri, Bacău, 20 (2010), No. 1, 5-12

[6] Akkouchi, M. and Popa, V., Weak posedness of a fixed point problem for mappings satisfying an implicit relation, Demonstratio Math., 43 (2010), No. 4, 923-929

[7] Akkouchi, M. and Popa, V., Well - posedness of fixed point problem for two mappings, to appear

[8] Babu, G. V. R., Sandhyas, M. L. and Kameswari, M. V. R., A notion of a fixed point theorem of Berinde on weak contractions, Carpathian J. Math., 24 (2008), No. 1, 8-12

[9] Berinde, V., On the approximation of fixed points of weak contractive mappings, Carpathian J. Math., 19 (2003), No. 1, 7-22

[10] Berinde, V., Approximating fixed points of weak contractions using the Picard itterations, Nonlinear Anal. Forum, 9 (2004), No. 1, 43-53

[11] Berinde, V., General constructive fixed point theorems for Ciric type almost contractions in metric spaces, Carpathian J. Math., 24 (2008), No. 2, 10-19

[12] Berinde, V., Approximating common fixed points of noncommuting almost contraction in metric spaces, Fixed Point Theory, 11 (2010), No. 2, 179-188

[13] De Blassi, F. G. and Myjak, J., Sur la porosite de contractions sans point fixe, Comptes Rend. Acad. Sci. Paris, 308 (1989), 10-19

[14] Jungck, G., Common fixed points for noncontinuous nonself maps on a nonnumeric space, Far. East J. Math. Sci. 4 (1996), No. 2, 195-215

[15] Lahiri, B. K. and Das, P., Well posedness and porosity of certain classes of operators, Demonstratio Math., 38 (2008), $170-176$

[16] Pant, R. P., Common fixed point for commuting mappings, J. Math. And Appl., 188 (1994), 436-440

[17] Pant, R. P., Common fixed point for four mappings, Bull. Calcutta Math. Soc., 90 (1998), 281-286

[18] Popa, V., Fixed point theorems for implicit contractive mappings, St. Cerc. St. Ser. Mat., Univ. Bacău, 7 (1997), $129-133$

Received: 21.10.2011; In revised form: 04.08.2012; Accepted: 06.09.2012

2010 Mathematics Subject Classification. c47H10, 54H25.

Key words and phrases. Coincidence point, fixed point, almost contraction, generalized contraction of type $(B)$, implicit relation. 
[19] Popa, V., Common fixed point theorems for compatible mappings of type (A) satisfying an implicit relation, St. Cerc. St. Ser. Mat., Univ. Bacău, 9 (1999), 165-173

[20] Popa, V., Some fixed point theorems for compatible mappings satisfying an implicit relation, Demonstratio Math., 32 (1999), 157-162

[21] Popa, V., Well - posedness of fixed point problem in orbitally complete metric spaces, St. Cerc. St. Ser. Mat., Univ. Bacău, No. 16, suppl. (2006) 209-214

[22] Popa, V., Well - posedness of fixed point problem in compact metric spaces, Bull. Math. Inform. Physics Series, Petroleum - Gas Univ. Ploieşti, 60 (2008), No. 1, 1-4

[23] Reich, S. and Zaslawski, A. J., Well - posedness of a fixed point problem, Far. East J. Math. Sci., Special Volume, (2001), Part. III, 391-401

DEPARTMENT OF MATHEMATICS AND INFORMATICS

FACULTY OF SCIENCES

"VASILE ALECSANDRI" UNIVERSITY OF BACĂU

CALEA MĂRĂŞEŞTI 157, 600115 BACĂU, ROMANIA

E-mail address: vpopa@ub. ro 